\title{
Rol de juego y características del saque en voleibol infantil femenino
}

\section{In game role and serve characteristics in Under-14 female volleyball}

\author{
Fernández-Echeverría, C. ${ }^{1}$, Claver, F. ${ }^{1}$, Gil, A. ${ }^{2}$, Del Villar, F. ${ }^{1}$ y Moreno, M.P. ${ }^{1}$ \\ 1 Facultad de Ciencias del Deporte. Universidad de Extremadura. Espańa. \\ 2 Facultad de Ciencias del deporte. Universidad Católica San Antonio de Murcia. \\ Recibido: 10/02/2014; Aceptado: 06/09/2014
}

\begin{abstract}
Resumen: El objetivo principal de esta investigación fue analizar las características del saque en función del rol de juego en voleibol infantil femenino. La muestra estuvo compuesta por 1229 acciones de saque, correspondientes a la observación de los 18 equipos participantes en el Campeonato España de Selecciones autonómicas en categoría infantil femenino. Las variables de estudio fueron: rol de juego, zona de origen de saque, tipo de saque, técnica de golpeo, eficacia del saque, zona de recepción y función del receptor. Los resultados determinaron una asociación significativa del rol de juego con el origen de saque, el tipo de saque, la técnica de golpeo y la eficacia de saque. Sin embargo, no aparecen asociaciones de ningún rol de juego con variables que muestren la intención de dirigir el saque hacia jugadoras concretas, evitando al libero, o dirigir el saque a zonas determinadas del campo contrario. Palabras claves: Función en juego, servicio, etapas de formación, voleibol.
\end{abstract}

Abstract: The main objective of this study was to analyze the serve characteristics depending on the in-game role, in female formative stages. The sample was comprised of 1229 serves, corresponding to the observation of the 18 teams participating in the Under-14 category Spanish Championship in 2010. The studied variables were: in-game role, serve zone, serve type, striking technique, reception zone, receiver player and serve effectiveness. The results showed a significant association between the in-game role with serve zone, serve type, striking technique and serve effectiveness. However, there is not a association between the in-game with variables that reflect the intention to direct the serve to a specific players or specific area were found.

Keywords: in-game role, service, formative stages, volleyball.

\section{Introducción}

El voleibol es un deporte de cooperación-oposición, destacando el saque como la única acción en la que el jugador tiene el $100 \%$ del control sobre la pelota (Ureña, 1998).

A lo largo de la historia, numerosos cambios reglamentarios han afectado a esta acción técnico-táctica, entre los que destacamos: el cambio del sistema de puntuación del «cambio de saque» a «fase punto total» o «Rally Point System», por lo que en voleibol, cada jugada supone punto; la incorporación del jugador líbero, por lo que cada equipo tiene la opción de registrar al final de la lista de 12 jugadores, un jugador especializado en defensa que suele intervenir en acciones de defensa y recepción; la ampliación de la zona de saque a todo el ancho de la línea de fondo (REFVB, 2013: p.18), permitiendo la realización de saques con nuevas trayectorias que podría dificultar la recepción del equipo contrario, y finalmente en 1999, la FIVB aprobó otra nueva reforma, por la que el balón podía contactar con la red en el saque (REFVB, 2013: p. 34), favoreciendo que los jugadores arriesgaran más en la realización del saque.

El saque paso de ser una acción a través de la cual se inicia el juego, a ser un arma de ataque (Coleman, 2009; Monge, 2007; Quiroga et al., 2010), pudiendo determinar el rendi-

Dirección para correspondencia [Correspodence address]: Carmen Fernández Echeverría. Facultad de Ciencias del Deporte. Universidad de Extremadura. Av. Universidad, s/n. 10071 Cáceres (España). E-mail: cafernandeze.unex.es miento de un equipo (Drikos, Kountouris, Laios, y Laios, 2009). Por ello, una de las acciones de juego a la que los entrenadores e investigadores han dado gran importancia, es el saque (Moraes, Mesquita, y Costa, 2008).

En voleibol, como ocurre en el resto de los deportes colectivos existe un proceso largo de formación de sus jugadores antes de llegar al alto rendimiento. Este proceso de formación se compone de una fase de iniciación que se caracteriza por una oferta motriz amplia y variada para ir pasando por diversas fases o etapas donde va surgiendo la especialización de los jugadores por puestos específicos, entre los que se diferencian colocadores, opuestos, receptores-atacantes, centrales (Herrera, Ramos y Mirella, 1996) y líberos. La asignación de estos puestos específicos se realiza atendiendo a características físicas, técnicas y psicológicas, ya que cada función en juego requiere unas determinadas particularidades. Aragundi (2006), Herrera, Ramos y Mirella (1996), y Selinger y Ackermann-Blount (1992) indican que el opuesto suele ser un jugador con un potente ataque y un saque en salto que se caracteriza por su agresividad, lo que condiciona en gran medida la recepción del equipo contrario; los centrales, son los encargados de efectuar ataques rápidos y variados por el centro, con un saque agresivo, siendo los bloqueadores más potentes del equipo; los receptores-atacantes son jugadores con gran responsabilidad en recepción, dominan una gran variabilidad de ataques, y suelen realizar un saque no con excesiva potencia pero con una cierta intención táctica, tratando de dirigir el balón hacia un jugador 
determinado (receptor más débil o atacante con peligro) o zona concreta (zona de interferencia entre dos jugadores receptores); el colocador debe poseer una alta capacidad combinativa en el pase, tener muy buena defensa en campo y tener un saque dirigido y efectivo (Gil, Moreno, Moreno, García-González y Del Villar, 2010), es una de las funciones en juego que debe tener un alto nivel de pensamiento táctico, debiendo conocer muy bien a sus compañeros y adversarios en la faceta de ataque como de defensa (Moutinho, 2000), ya que debe tomar decisiones críticas en el juego de ataque (Mesquita y Graca, 2002); y el líbero es el jugador especialista en defensa, actuando solo en la zona zaguera del campo, sustituyendo a jugadores de baja eficacia defensiva o en recepción que se encuentran en dicha zona (no puede realizar la acción de saque, bloquear y atacar ningún balón que se encuentre por encima de la red, desde ninguna zona del campo).

En voleibol de alto nivel se ha observado que las características del saque difieren entre los jugadores con diferentes roles de juego (Quiroga et al., 2010; Quiroga et al., 2012) y que en etapas de formación, aunque son dos realidades diferentes y la especialización no está del todo determinada, existe una ligera diferencia en las características del saque en función del rol de juego (Gil et al., 2010). Por ello, el objetivo principal de este trabajo fue analizar las características del saque considerando el rol de juego en etapas iniciales de formación en voleibol, como es la categoría infantil femenina.

\section{Método}

\section{Participantes}

La muestra del estudio estuvo compuesta por 1229 acciones de saque, correspondientes a la observación de los 18 equipos femeninos $(\mathrm{M}=68.27, \mathrm{SD}=26.76$ saques por partido) participantes en el Campeonato España de Selecciones autonómicas de 2010, en categoría infantil.

Los saques analizados, corresponden a la observación de un partido de cada uno de los equipos.

\section{Variables}

Las variables de estudio consideradas fueron las siguientes:

- Rol de juego: definido como el rol en juego del jugador que efectúa el saque. Se diferencian cuatro roles de juego:

- Colocador: el saque es realizado por un colocador.

- Central: el saque es realizado por un central.

- Opuesto: el saque es realizado por un opuesto.

- Receptor-atacante: el saque es realizado por un receptor-atacante.
- Zona de origen del saque: definido como la zona desde donde se realiza el saque. Se distinguen tres zonas de origen:

- Zona 1: el saque es realizado en la franja de tres metros de ancho, desde la línea lateral derecha y detrás de la línea de fondo.

- Zona 6: el saque es realizado en la franja de tres metros de ancho ubicada a tres metros de las líneas laterales del campo y detrás de la línea de fondo.

- Zona 5: el saque es realizado en la franja de tres metros de ancho, desde la línea lateral izquierda y detrás de la línea de fondo.

- Tipo de saque: definido como la tipología de saque empleada por el jugador, considerando la ubicación del jugador en el momento de contacto con el balón. Se distinguen dos tipos de saque:

- Apoyo: saque en el cual el jugador se encuentra en contacto con el suelo en el momento del golpeo del balón.

- Salto: saque en el cual el jugador no tiene los pies en contacto con el suelo en el momento del golpeo al balón.

- Técnica de golpeo: definido como el tipo de técnica de saque empleada por el jugador, considerando la trayectoria de vuelo del balón tras el golpeo. Se distinguen dos tipos de técnica de golpeo:

- Potente: saque en el cual el jugador golpea imprimiendo velocidad y fuerza al balón.

- Flotante: saque en el cual el jugador golpea imprimiendo una trayectoria oscilatoria al balón.

- Eficacia: definido como el rendimiento o efecto obtenido con el saque. Se han diferenciado los siguientes valores:

- Error: se falla el saque.

- Continuidad: saque que permite que el balón se ponga en juego.

- Punto: saque que supone la obtención de un punto.

- Zona de recepción: definido como la zona donde se realiza la recepción del saque. Se diferencian cuatro zonas:

- Pasillo de 1: la recepción se realiza en el pasillo de tres metros de ancho por nueve de largo ubicado en la parte derecha del campo.

- Pasillo de 6: la recepción se realiza en el pasillo de tres metros de ancho por nueve de largo ubicado en la parte central del campo.

- Pasillo de 5: la recepción se realiza en el pasillo de tres metros de ancho por nueve de largo ubicado en la parte izquierda del campo.

- Zona de Interferencia: el balón es enviado a una zona intermedia y de conflicto entre dos receptores. 
- Función del receptor: definido como el rol o función en juego del jugador al que es dirigido el saque para su recepción. Se diferencian cuatro funciones de juego:

- Colocador: el saque es dirigido y recibido por el colocador o jugador que cubre a éste.

- Atacante-Delantero: el saque es dirigido y recibido por el atacante delantero.

- Otros: el saque es dirigido y recibido por jugadores con funciones de juego diferentes a las mencionadas anteriormente.

\section{Procedimiento}

Mediante la observación sistemática del saque se realizó la medida de las variables anteriormente indicadas. Las grabaciones de los partidos fueron realizadas con una cámara digital SONY HDR-XR155 sobre formato M2TS. Dicha cámara se ubicaba en uno de los fondos de la cancha de juego a una altura de cinco metros sobre el suelo, para obtener un óptimo plano de visión.

Para garantizar la fiabilidad de la observación, después de recoger las imágenes de vídeo y con anterioridad al proceso de codificación, un observador con experiencia en esta función (jugador de voleibol y estadístico oficial del data-volley), fue entrenado para observar las variables de estudio. En las diferentes sesiones de entrenamiento de observadores se emplearon muestras con características diferentes, superándose el 10\% de la muestra total, indicado por Tabachnick y Fidell (2007). Se alcanzaron unos valores de Kappa de Cohen inter- observador, superiores a 0,81 , en la observación de todas las variables, a partir de la cuarta sesión de entrenamiento, valor mínimo que se considera para un acuerdo casi perfecto (Landis y Koch, 1977). Para garantizar la fiabilidad temporal de la medida, la misma codificación fue desarrollada en dos ocasiones, con una diferencia temporal de 10 días, obteniéndose valores de Kappa de Cohen superiores a 0,81.

\section{Análisis estadístico de los datos}

Se realizó un análisis inferencial, basándonos en las tablas de contingencia, los valores de Chi-cuadrado y V de Cramer, para conocer las posibles relaciones existentes entre las diferentes variables consideradas en el estudio y el rol de juego, garantizando las condiciones necesarias para aplicar de forma válida la prueba Test de Chi Cuadrado (la frecuencia mínima esperada es mayor que uno y no hay más del 20\% de las casillas de la tabla con frecuencias esperadas menor que cinco). El nivel de significación estadística considerado fue de $\mathrm{p}<0.05$.

\section{Resultados}

\section{- Rol de juego- Zona de origen de saque}

El rol de juego se asoció significativamente con el origen de saque $\left(\mathrm{x}^{2}=48.168 ; \mathrm{V}\right.$ de Cramer $\left.=.144 ; \mathrm{p}<.001\right)$. Las celdas que contribuyen de manera positiva a esta asociación son: el saque desde 5 con el central y el saque desde zona 1 con el opuesto.

Tabla 1. Tabla de contingencia Rol de juego- Zona de origen de saque.

\begin{tabular}{|c|c|c|c|c|c|c|}
\hline & & & \multicolumn{3}{|c|}{ Zona de origen de saque } & \multirow[b]{2}{*}{ Total } \\
\hline & & & Saque desde zona 1 & Saque desde zona 5 & Saque desde zona 6 & \\
\hline \multirow[t]{12}{*}{ Rol de juego } & Colocador & Recuento & 105 & 18 & 229 & 352 \\
\hline & & Recuento esperado & 97.4 & 36.7 & 218.0 & 352.0 \\
\hline & & Residuo corregido & 1.1 & -3.9 & 1.4 & \\
\hline & Central & Recuento & 57 & 57 & 178 & 292 \\
\hline & & Recuento esperado & 80.8 & 30.4 & 180.8 & 292.0 \\
\hline & & Residuo corregido & -3.6 & 5.8 & -.4 & \\
\hline & Opuesto & Recuento & 44 & 9 & 62 & 115 \\
\hline & & Recuento esperado & 31.8 & 12.0 & 71.2 & 115.0 \\
\hline & & Residuo corregido & 2.7 & -1.0 & -1.9 & \\
\hline & Receptor-atacante & Recuento & 134 & 44 & 292 & 470 \\
\hline & & Recuento esperado & 130.0 & 49.0 & 291.0 & 470.0 \\
\hline & & Residuo corregido & .5 & -1.0 & .1 & \\
\hline \multirow[t]{3}{*}{ Total } & & Recuento & 340 & 128 & 761 & 1229 \\
\hline & & Recuento esperado & 340.0 & 128.0 & 761.0 & 1229.0 \\
\hline & & $\%$ del total & $27.7 \%$ & $10.4 \%$ & $61.9 \%$ & $100.0 \%$ \\
\hline
\end{tabular}




\section{- Rol de juego- Tipo de saque}

El rol de juego se asoció significativamente con el tipo de saque $\left(\mathrm{x}^{2}=45.895\right.$; $\mathrm{V}$ de Cramer $\left.=.193 ; \mathrm{p}<.001\right)$. Las celdas que contribuyen de manera positiva a esta asociación son: el saque en apoyo con el colocador y el central, y el saque en salto con el opuesto.

Tabla 2. Tabla de contingencia Rol de juego-Tipo de saque.

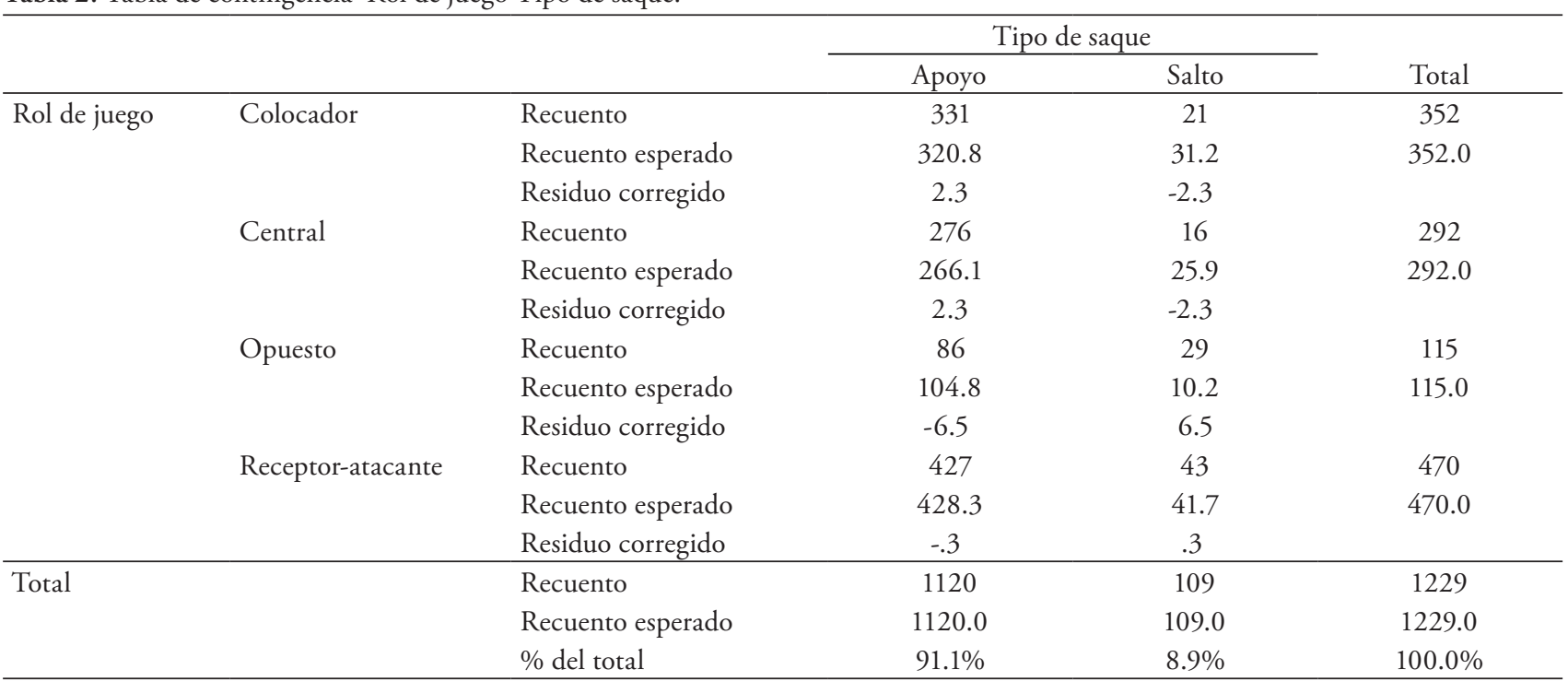

casillas (.0\%) han esperado un recuento menor que 5. El recuento mínimo esperado es 10.20

\section{- Rol de juego- Técnica de golpeo}

El rol de juego se asoció significativamente con la técnica de golpeo $\left(\mathrm{x}^{2}=9.349 ; \mathrm{V}\right.$ de Cramer $\left.=.087 ; \mathrm{p}=.025\right)$. Las celdas que contribuyen de manera positiva a esta asociación son: el saque potente con el central y el saque flotante con el opuesto.

Tabla 3. Tabla de contingencia Rol de juego- Técnica de golpeo.

\begin{tabular}{|c|c|c|c|c|c|}
\hline & & & Técni & rolpeo & \\
\hline & & & Saque flotante & Saque potente & Total \\
\hline Rol de juego & Colocador & Recuento & 198 & 154 & 352 \\
\hline & & Recuento esperado & 193.3 & 158.7 & 352.0 \\
\hline & & Residuo corregido & .6 & -.6 & \\
\hline & Central & Recuento & 145 & 147 & 292 \\
\hline & & Recuento esperado & 160.4 & 131.6 & 292.0 \\
\hline & & Residuo corregido & -2.1 & 2.1 & \\
\hline & Opuesto & Recuento & 76 & 39 & 115 \\
\hline & & Recuento esperado & 63.2 & 51.8 & 115.0 \\
\hline & & Residuo corregido & 2.5 & -2.5 & \\
\hline & Receptor-atacante & Recuento & 256 & 214 & 470 \\
\hline & & Recuento esperado & 258.1 & 211.9 & 470.0 \\
\hline & & Residuo corregido & -.3 & .3 & \\
\hline Total & & Recuento & 675 & 554 & 1229 \\
\hline & & Recuento esperado & 675.0 & 554.0 & 1229.0 \\
\hline & & $\%$ del total & $54.9 \%$ & $45.1 \%$ & $100.0 \%$ \\
\hline
\end{tabular}

casillas $(.0 \%)$ han esperado un recuento menor que 5 . El recuento mínimo esperado es 51.84 


\section{- Rol de juego- Eficacia}

El rol de juego se asoció significativamente con la eficacia del saque $\left(\mathrm{x}^{2}=15.243 ; \mathrm{V}\right.$ de Cramer $\left.=.079 ; \mathrm{p}=.018\right)$. Las celdas que contribuyen de manera positiva a esta asociación son: la continuidad del saque con el colocador y el error de saque con el receptor-atacante.

Tabla 4. Tabla de contingencia Rol de juego-Eficacia de saque.

\begin{tabular}{|c|c|c|c|c|c|c|}
\hline & & & \multicolumn{3}{|c|}{ Eficacia de saque } & \multirow[b]{2}{*}{ Total } \\
\hline & & & Punto saque & Error saque & Continuidad saque & \\
\hline \multirow[t]{12}{*}{ Rol de juego } & Colocador & Recuento & 40 & 241 & 71 & 352 \\
\hline & & Recuento esperado & 57.3 & 223.1 & 71.6 & 352.0 \\
\hline & & Residuo corregido & -3.0 & 2.3 & -.1 & \\
\hline & Central & Recuento & 45 & 192 & 55 & 292 \\
\hline & & Recuento esperado & 47.5 & 185.1 & 59.4 & 292.0 \\
\hline & & Residuo corregido & -.5 & 1.0 & -.7 & \\
\hline & Opuesto & Recuento & 24 & 62 & 29 & 115 \\
\hline & & Recuento esperado & 18.7 & 72.9 & 23.4 & 115.0 \\
\hline & & Residuo corregido & 1.4 & -2.2 & 1.4 & \\
\hline & Receptor-atacante & Recuento & 91 & 284 & 95 & 470 \\
\hline & & Recuento esperado & 76.5 & 297.9 & 95.6 & 470.0 \\
\hline & & Residuo corregido & 2.3 & -1.7 & -.1 & \\
\hline \multirow[t]{3}{*}{ Total } & & Recuento & 200 & 779 & 250 & 1229 \\
\hline & & Recuento esperado & 200.0 & 779.0 & 250.0 & 1229.0 \\
\hline & & $\%$ del total & $16.3 \%$ & $63.4 \%$ & $20.3 \%$ & $100.0 \%$ \\
\hline
\end{tabular}

0 casillas $(.0 \%)$ han esperado un recuento menor que 5 . El recuento mínimo esperado es 18.71

- Rol de juego - Zona de recepción.

El rol de juego no se asoció significativamente con la zona de recepción $\left(\mathrm{x}^{2}=15.694 ; \mathrm{V}\right.$ de Cramer $\left.=.071 ; \mathrm{p}=.074\right)$.

\section{- Rol de juego - Función del receptor.}

El rol de juego no se asoció significativamente con la función del receptor $\left(\mathrm{x}^{2}=6.382 ; \mathrm{V}\right.$ de Cramer $\left.=.056 ; \mathrm{p}=.382\right)$.

\section{Discusión}

El objetivo principal de este trabajo fue analizar las características del saque considerando el rol de juego en voleibol infantil femenino, estudiando la asociación de las variables zona de origen de saque, tipo de saque, técnica de golpeo, eficacia del saque, zona de recepción y función del receptor, con la función en juego en voleibol.

En los resultados se encontró una asociación significativa entre la variable rol de juego y la zona de origen de saque, de tal manera que el central se asocia positivamente con el saque desde zona 5 y el opuesto con el saque desde zona 1.

Los resultados mostrados siguen la línea de estudios rea- lizados anteriormente en etapas de formación, como el de Gil et al. (2010), donde encontraron asociación significativa entre el origen de saque y la función en juego. En alto nivel femenino, aunque sean realidades diferentes a la de etapas de formación, también encontraron asociación significativa entre dichas variables (Maia y Mesquita, 2006; Quiroga et. al, 2010). Más concretamente, los jugadores centrales suelen realizar principalmente su saque desde zona 5 y los colocadores y opuestos desde zona 1 (FroHner y Zimmermann, 1996; Maia y Mesquita, 2006; Quiroga et. al, 2010). Dichos resultados han sido justificados por la intención de los jugadores de reducir la distancia a recorrer desde la zona de saque hasta la zona de defensa a la que deben acudir posteriormente (Gil et. al, 2010, Moreno, Molina y Santos, 2008; Ureña, Santos, Martínez, Calvo y Ońa, 2000). Los resultados expuestos en etapas de formación indican, que desde etapas de formación, algunos jugadores realizan el saque desde zonas concretas, esto puede ser debido por la intención de realizar el saque desde zonas cercanas a las que posteriormente tendrán que cubrir los jugadores en defensa, facilitando así la incorporación a las mismas o bien por la búsqueda de zonas de saque que les permitan realizar un saque seguro (que pase al otro campo), en función de sus capacidades técnicas. Por ello, en 
el proceso de entrenamiento, para dotar a los jugadores de la capacidad de sacar desde cualquier zona del fondo del campo, el entrenador debe tener en cuenta este aspecto, trabajando con sus jugadores la variabilidad del saque mediante la realización de esta acción técnico-táctica desde diferentes zonas.

En la asociación entre la variable función en juego con tipo de saque y técnica de golpeo, los resultados obtenidos muestran una asociación significativa entre dichas variables, de tal manera que el central se asocia de manera positiva con el saque en apoyo y potente, el colocador con el saque en apoyo y flotante y el opuesto con el saque en salto y flotante.

En estudios anteriores, en etapas de formación (Gil et. al, 2010), también encontraron asociación entre el tipo de saque y la técnica de golpeo con la función del sacador, mostrando resultados similares a los nuestros, donde la colocadora se asociaba positivamente con el saque en apoyo flotante y la central con saque en apoyo potente. Sin embargo, en dicho estudio, la jugadora opuesta muestra una asociación con el saque en salto potente, mientras que en nuestro estudio dicha jugadora se asocia con un saque en salto pero flotante. Dichas diferencias pueden ser debidas a la muestra, ya que el estudio de Gil et al. (2010), se realiza en categoría infantil y cadete femenino, y en nuestro estudio, solo en infantil femenino. Esto muestra, que aunque las opuestas en infantiles empiecen a destacar con un saque en salto, todavía se encuentran en proceso de formación y no son capaces de realizarlo en potencia. Por ello, se sugiere que en el entrenamiento de saque en voleibol, en etapas de formación, los entrenadores tengan en cuenta las características antropométricas de sus jugadoras (Stamm, 1999), trabajando la realización de saques de más simples tecnicamente a más complejos.

La asociación entre el rol de juego y el tipo de saque fueron obtenidas también por estudios precedentes en alto rendimiento femenino (Maia y Mesquita, 2006 y Quiroga et. al, 2010). Más concretamente, en el estudio de Quiroga et al. (2010), con una muestra de jugadoras de alto rendimiento, indicaron que las opuestas buscan potencia mediante el saque en salto potente (Ejem, 2001) y las colocadoras, muestran una clara intencionalidad táctica, a partir del saque en apoyo flotante (Frohner y Murphy, 1995).

De acuerdo con los resultados mostrados, en etapas de formación en femenino, se comienza a observar características diferentes en el saque en función del rol de juego, por lo que es importante tener en cuenta esta consideración en el proceso de entrenamiento (Maia y Mesquita, 2006), incluyendo los tipos de saques más usados en esta categoría para entrenar nuestra recepción. Sin embargo, no podemos olvidar que se encuentran en proceso de formación por lo que las características del saque deben ser acordes a sus capacidades (Cotê, 1999; Cotê \& Hay 2002; Cotê, Baker \& Abernethy, 2003).

En la asociación entre la variable función en juego con eficacia de saque, nuestros resultados encontraron una asociación significativa entre dichas variables, de tal manera que el colocador se asocia positivamente con la continuidad de saque y el receptor-atacante con el error de saque.

Estudios previos realizados en etapas de formación como el de Gil et al., (2010), a diferencia de nuestro estudio, no encontraron asociación significativa entre el rol de juego y la eficacia de saque. Esto puede ser debido, como ya hemos comentado, que en el estudio de Gil et al., (2010) se utilizó una muestra de cadetes e infantiles, mientras que en nuestro estudio utilizamos una muestra solo en infantiles.

Estudios en alto nivel femenino muestran en sus resultados diferente eficacia del saque en función del rol del sacador (Afonso y Mesquita, 2011; Afonso, Mesquita, Marcelino y Silva, 2010), más concretamente, en el estudio de Quiroga et al., (2010), en línea con nuestros resultados, indican que la colocadora es la jugadora que menos errores comete en el saque, por el contrario, es la receptora-atacante la jugadora que más falla en dicha acción. Por lo que sugerimos, que en etapas de formación los jugadores que cometen muchos errores, contemplen otro tipo de saque que le suponga menor riesgo (Over, 1993).

A partir de los resultados presentados, podemos indicar que en categorías de formación, a pesar de existir una cierta especialización de los jugadores y aunque los patrones de ejecución del saque y la eficacia, tengan como último referente a los del alto rendimiento, no obtuvimos asociación del rol de juego con el punto directo. Dichos resultados, nos indican que la efectividad del saque en estas etapas se centra principalmente en permitir la continuidad de saque. Por ello, sugerimos a los entrenadores en etapas de formación, que en el proceso de entrenamiento los jugadores trabajen saques que no les supongan un riesgo excesivo (Molina, Santos del Campo, Barriopedro, y Delgado, 2004).

Finalmente, las variable función en juego del sacador con zona de recepción y función del receptor no presentaron una asociación significativa. Nuestros resultados, difieren de los obtenidos por Gil et al., (2010), donde en su estudio en categoría cadete e infantil femenino si encontraron asociación entre el rol de juego y la zona de recepción. Dichos resultados pueden justificarse debido a que en su muestra compuesta no solo de categoría infantil, sino también por jugadoras cadetes, muestran una clara intencionalidad táctica, enviando el balón a un determinado jugador del equipo adversario o a una zona concreta del campo contrario (Gil, Moreno, Moreno, García y Del Villar, 2009), mientras que las jugadoras infantiles de nuestro estudio, en proceso de formación, no tiene adquirido un dominio técnico que le permita dirigir el saque a determinadas zonas.

En contextos diferentes como es en alto nivel, en el estudio de (Quiroga et. al, 2010) no encontraron asociación significativa entre el rol de juego y la función del receptor, indicando que en alto nivel las sacadoras, independientemente de su función en juego, no difieren en el envío del balón a receptoras con diferentes funciones en juego. 
Finalmente, nuestros resultados muestran que en estas etapas de formación, más concretamente en categoría infantil femenino, se está iniciando un proceso de especialización en el que comienzan a apreciarse en jugadoras con determinados roles de juego, características concretas en la realización del saque. Dichas características concretas son la realización de saques desde diferentes zonas de origen, utilizando diferentes tipos y técnicas de saque y obteniendo eficacia distinta para cada rol de juego. Sin embargo, en estas etapas de formación, no se encuentran diferencias entre roles de juego de las jugadoras, en la intención de dirigir el saque a determinadas zonas o a jugadores concretos, centrándose más en su propia acción técnico- táctica.

Agradecimientos: Este trabajo ha sido realizado dentro del Proyecto financiado por el Ministerio de Ciencia e Innovación "Sistema Mas $\mathrm{Vb}$ de evaluación competitiva y orientación técnica para la Superliga Española de Voleibol" (DEP2011-27503).

\section{Bibliografía}

1. Afonso, J. y Mesquita, I. (2011). Determinants of block cohesiveness and attack efficacy, in high- level women's volleyball. European Journal of Sport Science 11(1), 69-75.

2. Afonso, J., Mesquita, I., Marcelino, J. y Silva, J. (2010). Analysis of the setter's tactical action in high-performance women's Volleyball. Kinesiology 42(1), 82-89.

3. Aragundi, C. (2006). Observación y análisis de la colocación en voleibol. Universidad da Coruña, Departamento de Educación Fisica y Deportiva. A Coruña.

4. Coleman, S. (2009). A Three- dimensional kinematic analysis of the volleyball jump serves. Journal of Sports Sciences, 11, 295-302.

5. Côté, J. (1999). The influence of the family in the development of talent in sport. The sport psychologist, 13 (4), 395-417.

6. Côté, J. y Hay, J. (2002). Children's involvement in sport: A developmental perspective. In J. M. Silva, y D. E. Stevens (Eds.), Psychological foundations of sport. Boston: Allyn \& Bacon. Pp. 484-502.

7. Cote, J., Baker, J. y Abernethy, B. (2003). From play to practice. In Starkes, J.L. \& Ericsson, K. A (eds.), Expert performance in sports: Advances in research on sport expertis. United State: Human Kinetics. Pp 89-113.

8. Drikos, S., Kountouris, P., Laios, A. y Laios, Y. (2009). Correlates of team performance in volleyball. International Journal of Performance Analysis in Sport, 9(2), 149-156.

9. Ejem, M. (2001) Brief technical evaluation of the $27^{\text {th }}$ Olimpiad in Sydney. The Coach, 1, 6-12.

10. Fröhner, B. y Murphy, P. (1995). Tendencias observadas en los Campeonatos del Mundo Femeninos de 1994. International Volley Tech, 1/95,23-28.

11. Fröhner, B. y Zimmermann, B. (1996). "Juegos Olímpicos de 1996 en Atlanta: aspectos seleccionados de desarrollo en el voleibol masculino”. The coach, 4, 11-18.

12. Gil, A., Moreno, M. P., Moreno, A., García, L. y Del Villar, F. (2009). Estudio del conocimiento procedimental de jóvenes jugadores de voleibol durante la acción de saque. Libro de Actas del II Congreso Internacional de Deportes de Equipo. A Coruña: Espańa.

13. Gil, A., Moreno, M. P., Moreno, A., García-González, L. y Del Villar, F. (2010). Caracterización del saque de voleibol en categorías de formación atendiendo a la función del juego. Revista Internacional de Deportes Colectivos, 6, 37-61

14. Herrera, G., Ramos, J.L. y Mirella, J. (1996) Voleibol: manual de consulta operativa para el entrenador. 10 Ed. Bilbao: Federación Vasca de Voleibol.

15. Landis, J. y Koch, G. (1977). The measurement of observer agreement for categorical data. Biometrics, 33, 159-174.

16. Maia, N. y Mesquita, I. (2006). Characterizacion of the serve in the female Volleyball in high competitive outcome. In Actas VII World Congress of Performance Analysis of Sport. Szombathely.

17. Molina, J. J., Santos del Campo, J. A., Barriopedro, M. y Delgado, M.
Á. (2004). Análisis de juego desde el modelo competitivo: un ejemplo aplicado al saque en voleibol. Kronos, 5, 37-45.

18. Moreno, M.P., Molina, J.J. y Santos, J.A. (2008). El saque, sus variables y repercusiones. En Actas del Clinic Memorial Tońo Santo. Granada, España.

19. Mesquita, I. y Graça, A. (2002). Probing the strategic knowledge of an elite volleyball setter: a case study. International Journal of Volleyball Research, 5, 6-12

20. Monge, M. (2007). Construcción de un sistema observacional para el análisis de la acción de juego en voleibol. A Coruña: servicio de publicaciones.

21. Moraes, J., Mesquita, I. y Costa, G. (2008). Análise do jogo: tendências do saque e da recepção no voleibol de elevado rendimento. In Actas do XII Congresso de Ciencias do Desporto e Educaçao Física dos Países de Lengua Portuguesa. Paz, Dereitos Humanos e Inclusao Social. Porto Alegre.

22. Moutinho, C. (2000). Estudo da estrutura interna das acçôes da distribuição em equipas de voleibol de alto nivel de rendimento - contributo para a caracterização e prospectiva do jogador distribuidor. Dissertação apresentada às provas de doutoramento no ramo de Ciências do Desporto. Faculdade de Ciências do Desporto e de Educaçâo Física da Universidade do Porto.

23. Over, P. (1993). El saque con salto. Volley-Tech., 1, 21-25.

24. Quiroga, M.E.; García Manso, J.M.; Rodríguez-Ruiz, D.; Sarmiento, S.; De Saa, Y. y Moreno, M.P. (2010). Relationship between in-game role and service characteristics in elite women's volleyball. Journal of Strengh \& Conditioning Research, 24(9), 2316-2321.

25. Quiroga, M., Rodriguez-Ruiz, D., Sarmiento, S., Muchaga, L., Grigoletto, M. y Garcia-Manso, J. (2012). Characterisation of the Main Playing Variables Affecting the Service in High-Level Women's Volleyball. Journal Quantitative Analysis in Sports, 8 (1), 1-11.

26. RFEVB. Reglas Oficiales de Voleibol. 2013-2016. Real Federación Española Voleibol, Madrid.

27. Selinger, A. y Ackermann-Blound, J. (1992). Power Volleyball. París: Vigot.

28. Stamm, R. (1999). Methods for Testing Individual Abilities of 13-16-Year-Old Female Volleyball Players and Assessment of Their Proficiency in the Game. International Journal of Volleyball Research, 1(1), 50-56.

29. Tabachnick, B. G. y Fidell, L. S. (2007). Using multivariate statistics. Ed. Boston: Allyn and Bacon.

30. Ureña, A. (1998). Incidencia de la función ofensiva sobre el rendimiento de la recepción del saque en voleibol. Tesis Doctoral del Departamento Personalidad, Evaluación y Tratamiento Psicológico. Universidad de Granada.

31. Ureña, A., Santos, J.A., Martínez, M., Calvo, R.M. y Oña, A. (2000). La facilitación defensiva a través del saque en el voleibol femenino de alto nivel. European Journal of Human Movement. Motricidad, 6, 175-189. 